\title{
Tipología circadiana y problemas de salud mental
}

\author{
Juan M. Antúnez ${ }^{1}$, José F. Navarro ${ }^{1}$ y Ana Adan $2,3^{*}$ \\ ${ }^{1}$ Departamento de Psicobiologia. Facultad de Psicología. Universidad de Málaga \\ ${ }^{2}$ Departamento de Psiquiatría y Psicobiologia Clinica. Universitat de Barcelona \\ ${ }^{3}$ Instituto de Investigación en Cerebro, Cognición y Conducta (IR3C), Barcelona
}

\begin{abstract}
Resumen: La tipología circadiana (matutina, vespertina o intermedia) es una diferencia individual que se ha relacionado con numerosos aspectos de la salud mental. En este estudio se revisan los principales hallazgos publicados en el área. Tras la búsqueda bibliográfica en las principales bases de datos se seleccionaron un total de 70 artículos publicados en castellano e inglés entre los años 1990 y 2012, recogidos en las bases de datos ISI, Scopus y Medline, donde se muestra que los individuos vespertinos presentan una mayor prevalencia de trastorno afectivo estacional, depresión mayor, trastorno bipolar, esquizofrenia, trastornos de la conducta alimentaria, trastornos del sueño, conductas adictivas, TDAH y mayores niveles de ansiedad que los matutinos. La tipología vespertina se perfila como un factor de riesgo y la matutina como un factor protector para el desarrollo de diversas psicopatologías, apuntándose como posibles causas polimorfismos de los genes reloj, el jet-lag social y algunos rasgos de personalidad. La tipología circadiana debe considerarse en la evaluación, tratamiento y prevención de las psicopatologías, pues afecta al inicio, curso, remisión y recaída de las mismas. La utilización de terapia cronobiológica es un factor a tener en cuenta en el abordaje terapéutico cuando la expresión rítmica circadiana se halla alterada.

Palabras clave: revisión sistemática cualitativa; tipología circadiana; matutinidad-vespertinidad; salud mental; psicopatología.
\end{abstract}

Title: Circadian typology and problems in mental health.

Abstract: Circadian typology (morning-type, neither-type, and eveningtype) is an individual difference which has been related to numerous aspects of mental health. In this paper we present a review of the findings published on this topic. After searching in the main databases a total number of 70 works were selected, published in Spanish and English from 1990 to 2012 collected in the databases ISI, Scopus and Medline. These works show that individuals with evening-type typology exhibit a greater prevalence of seasonal affective disorder, mayor depression, bipolar disorder, schizophrenia, eating disorders, sleep disorders, addictive behaviours, ADHD, and higher anxiety levels than morning-type typology individuals. In this sense, the evening-type is considered as a factor of risk whereas the morning-type would be a protective factor for the development of several mental disorders. This could be a result of clock gene polymorphisms, social jet lag and some personality traits. Circadian typology must be considered in the evaluation, treatment and prevention of the mental disorders, as it affects to the start, course, remission and relapse of diverse problems of mental health. Chronobiological therapy must be also considered in the therapeutic approaching when the circadian rhythmical expression is altered.

Key words: qualitative systematic review; circadian typology; morningnesseveningness; mental health; psychopathology.

\section{Introducción}

Los ritmos circadianos, descritos por de Mairan en 1729 (como se cita en McClung, 2006), son ritmos biológicos de periodicidad aproximada de 24 horas, coincidiendo con el ciclo lumínico. Estos ritmos se generan endógenamente por los llamados marcapasos o relojes biológicos. En todas las especies vivas el sistema circadiano controla la actividad biológica de los patrones rítmicos diarios (Dardente y Cermakian, 2007). En los mamíferos existen numerosos relojes biológicos situados en diversas áreas cerebrales y en tejidos periféricos (Dardente y Cermakian, 2007), todos ellos controlados por el núcleo supraquiasmático del hipotálamo (Guo, Brewer, Lehman y Bittman, 2006). La mayoría de parámetros biológicos (temperatura corporal, secreción hormonal, sueño-vigilia, etc.) y comportamentales (alerta, atención, memoria, etc.) muestran una evidente ritmicidad circadiana (Silva, Albuquerque y Araujo, 2005; Wehr, 2001).

Los ritmos circadianos se hallan sincronizados a señales externas, siendo la principal el ciclo luz-oscuridad, y cambios en éstas requieren reajustes de fase. Un ejemplo de ello es el fenómeno conocido como jet lag, producido comúnmente tras la realización de un vuelo transmeridional, donde el reloj biológico debe reajustarse al ambiente externo durante más

* Dirección para correspondencia [Correspondence address]: Ana Adan. Departamento de Psiquiatría y Psicobiología Clínica, Facultad de Psicología, Campus Mundet, Universitat de Barcelona, 08035 Barcelona (España). E-mail: aadan@ub.edu o menos días dependiendo de la cantidad de zonas horarias modificadas (Vosko, Colwell y Avidan, 2010).

Los humanos presentan diferencias en la regulación de los ritmos circadianos, lo que suele evaluarse mediante cuestionarios auto-informados que presentan adecuadas propiedades psicométricas (Caci, Deschaux, Adan y Natale, 2009) y que tienen en cuenta diversos factores: hora preferida para levantarse, nivel de activación tras levantarse, momento del día en que el individuo se encuentra mejor y hora de la noche a la que la persona se encuentra cansada y siente la necesidad de dormir, entre otros (Adan y Almirall, 1991). Éstos aportan una puntuación en el continuo denominado matutinidad-vespertinidad, si bien existen puntos de corte para clasificar a los individuos en tres tipologías circadianas o cronotipos: matutinos, intermedios y vespertinos. Las personas matutinas se encuentran más sincronizadas con el ciclo luzoscuridad y los momentos horarios de sus valores máximos tanto de parámetros biológicos como comportamentales se producen más temprano -avanzados de fase- que en los vespertinos. Así, los individuos matutinos suelen acostarse y levantarse más temprano y sus máximos de actividad y rendimiento suelen producirse por la mañana, mientras que los vespertinos se acuestan y levantan más tarde y sus momentos de máxima actividad y rendimiento suelen producirse por la tarde (Bennett, Petros, Johnson y Ferraro, 2008; Schmidt, Collette, Cajochen y Peigneux, 2007). Los sujetos intermedios, por su parte, suelen situarse en posiciones entre los dos grupos extremos. La tipología intermedia es la más prevalente en adultos, pues está presente en el 60\% de la 
población, mientras que las tipologías vespertina y matutina tienen una prevalencia aproximada del $20 \%$ cada una (Adan y Natale, 2002).

El cronotipo se ve influenciado por la edad y el sexo. La tipología matutina es más común hasta los 10 años y pasados los 50 (Roenneberg et al., 2004). Además, la mayoría de las investigaciones sostienen que la tendencia hacia la matutinidad se va incrementando con el aumento de la edad (Adan et al., 2012; Adan, Lachica, Caci y Natale, 2010). Los estudios realizados también apuntan a una mayor prevalencia de vespertinidad en los varones (Adan et al., 2012; Adan y Natale, 2002), los cuales además aportan una mayor amplitud de sus funciones circadianas (Adan y Sánchez-Turet, 2001), lo que se ha interpretado como una mayor potencia endógena rítmica menos dependiente de las señales externas. Otros factores que parecen afectar a la tipología circadiana son las variables ambientales, como el hábitat, el clima, la longitud y la latitud (Achari y Pati, 2007; Randler, 2008a).

Durante las últimas dos décadas se han desarrollado numerosas investigaciones con el objetivo de delimitar la posible relación entre la tipología circadiana, la calidad de vida y la prevalencia de trastornos psiquiátricos (estado de ánimo, esquizofrenia, conducta alimentaria, del sueño, consumo de drogas, etc.). Asimismo, aunque no existen trabajos que hayan explorado dicha relación con los trastornos de personalidad, son diversos los estudios realizados sobre tipología circadiana y rasgos de personalidad. Éstos señalan la existencia de una relación entre la tipología vespertina y puntuaciones elevadas en neuroticismo (Tonetti, Fabbri y Natale, 2009), extraversión (Tankova, Adan y Buela-Casal, 1994), búsqueda de la novedad (Adan et al., 2010), búsqueda de sensaciones (Tonetti et al., 2010) e impulsividad (Muro, Gomà-i-Freixanet, Adan y Cladellas, 2011).

El presente estudio tiene como objetivo presentar las relaciones conocidas entre la tipología circadiana y diversos problemas de salud mental tales como trastornos del estado de ánimo, esquizofrenia y trastornos psicóticos, trastornos de la conducta alimentaria, trastornos del sueño, trastorno por uso de sustancias, problemas de ansiedad y trastorno por déficit de atención con hiperactividad (TDAH), a partir de la revisión sistemática de 70 artículos seleccionados de entre los publicados en los últimos 22 años. Nuestra hipótesis es que la tipología vespertina es un factor de riesgo y la matutina un factor de protección para el desarrollo de diversos problemas de salud mental.

\section{Método}

\section{Materiales y tipo de estudio}

A continuación se presenta un estudio teórico de revisión integrador según la clasificación de Fernández-Ríos y
Buela-Casal (2009). Los materiales empleados fueron los artículos de investigación y revisión seleccionados durante las búsquedas bibliográficas en las principales bases de datos, formando un total de 70 artículos (59 empíricos y 11 teóricos) publicados entre los años 1990 y 2012.

\section{Procedimiento y análisis de la información}

Durante los meses de octubre, noviembre y diciembre de 2012 se realizó una búsqueda en diferentes bases de datos con la finalidad de cubrir el mayor número de áreas temáticas. Las bases de datos empleadas fueron Scopus, Isi Web of Knowledge y PubMed.

Los términos empleados para realizar la búsqueda bibliográfica fueron: «circadian typology», «chronotype», «addictive», «addiction», «anxiety», «depression», «schizophrenia», «psychotic», «attention deficit hyperactivity disorder», «ADHD», «bipolar disorder», «anorexia», «bulimia», «dyssomnia» y «parasomnia». Los términos de búsqueda se limitaron al título, resumen y palabras clave. Dado el elevado número de artículos (273) que aparecieron, así como la probable inclusión de artículos irrelevantes, se establecieron criterios de inclusión y exclusión. Se incluyeron sólo artículos y revisiones publicados en castellano e inglés y, tras la lectura del resumen de cada uno de ellos, se seleccionaron los que trataban sobre la relación entre la tipología circadiana y alguno de los problemas de salud mental objetivo de estudio.

Los trabajos seleccionados se organizaron y analizaron en siete grupos temáticos de acuerdo a la clasificación propuesta por el DSM-IV-TR: trastornos del estado de ánimo (trastorno afectivo estacional, trastorno depresivo y trastorno bipolar), esquizofrenia y otros trastornos psicóticos, trastornos de la conducta alimentaria, trastornos del sueño, trastornos relacionados con sustancias, problemas de ansiedad y trastorno por déficit de atención con hiperactividad.

\section{Resultados}

Tras la evaluación de los 59 artículos empíricos y 11 teóricos, y como puede verse en la Figura 1, la depresión y el trastorno afectivo estacional y su relación con la tipología circadiana ha sido el problema de salud mental que mayor atención ha recibido por parte de la comunidad científica, seguidos por el trastorno bipolar, trastornos del sueño, trastornos de la conducta alimentaria, trastornos por uso de sustancias, problemas de ansiedad, trastornos psicóticos y TDAH. Asimismo, durante los últimos cuatro años se ha observado un incremento considerable de la producción científica. En la figura 2 se muestra la distribución, por año y trastorno psicológico, de los artículos analizados en esta revisión. 


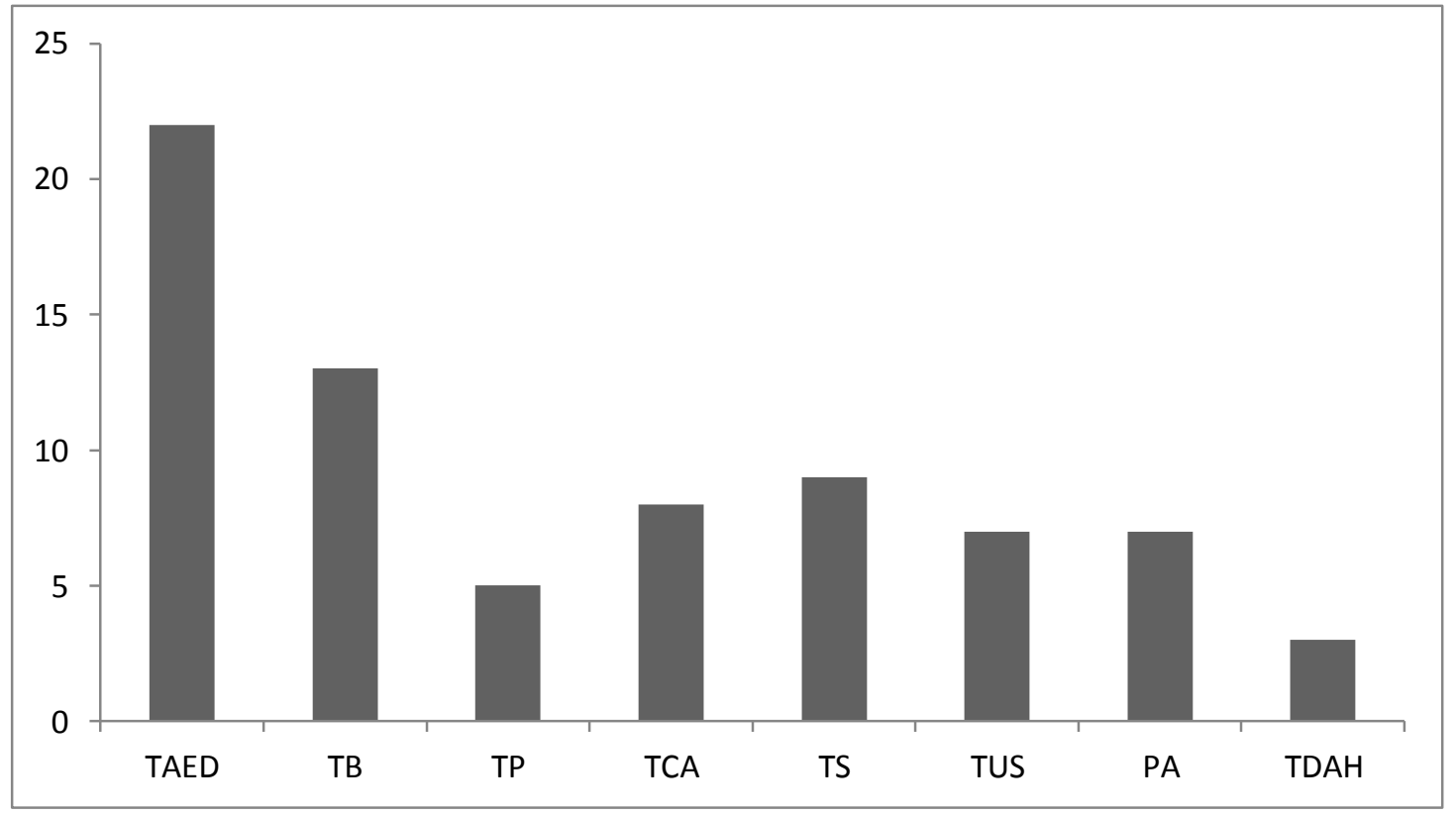

TAED: trastorno afectivo estacional y depresión; TB: trastorno bipolar; TP: trastornos psicóticos; TCA: trastornos de la conducta alimentaria; TS: trastornos del sueño; TUS: trastorno por uso de sustancias; PA: problemas de ansiedad; TDAH: trastorno por déficit de atención con hiperactividad.

Figura 1. Número de artículos encontrados en las diferentes bases de datos por cada trastorno psicológico.

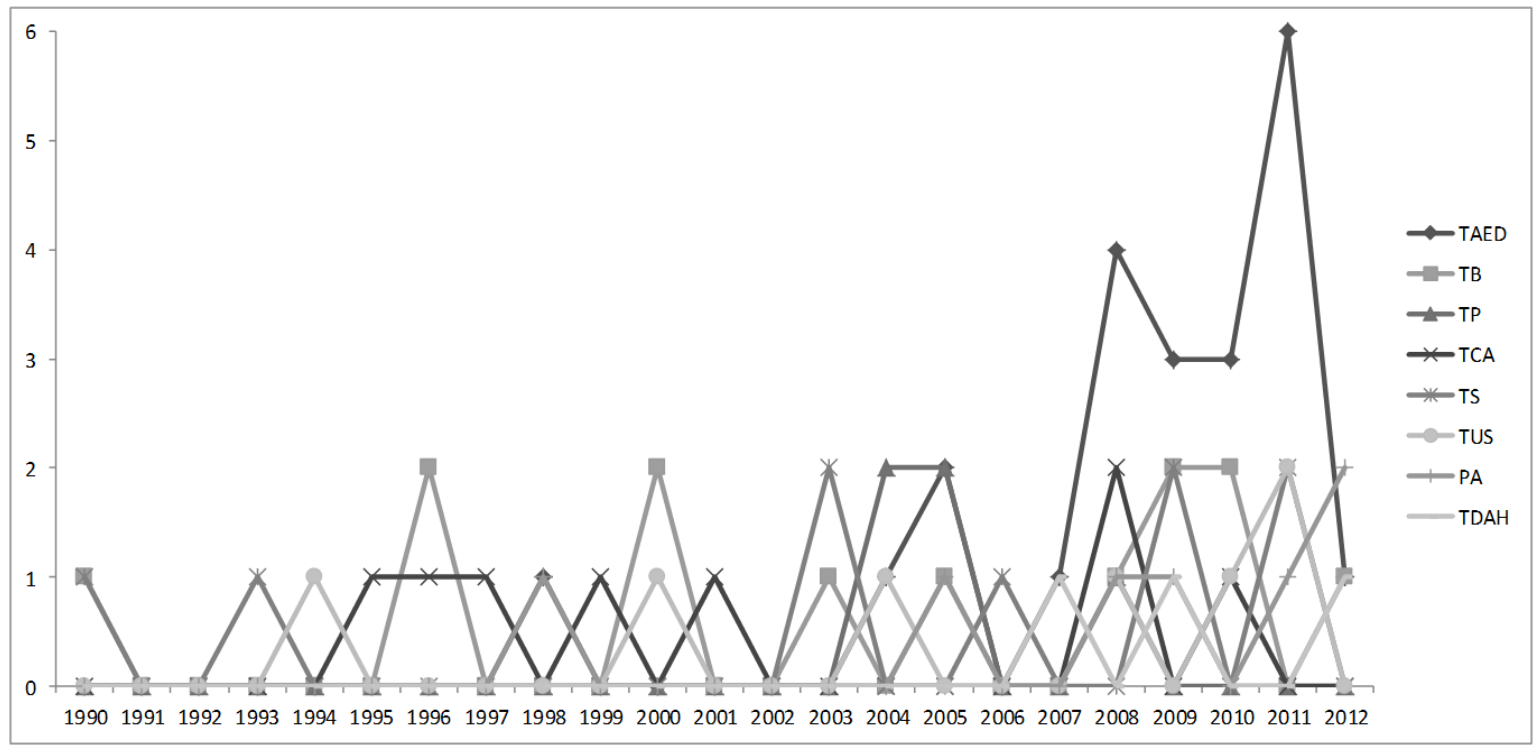

TAED: trastorno afectivo estacional y depresión; TB: trastorno bipolar; TP: trastornos psicóticos; TCA: trastornos de la conducta alimentaria; TS: trastornos del sueño; TUS: trastorno por uso de sustancias; PA: problemas de ansiedad; TDAH: trastorno por déficit de atención con hiperactividad.

Figura 2. Distribución de los artículos seleccionados por año y trastorno psicológico.

\section{Trastornos del estado de ánimo}

La tipología circadiana se ha implicado con la prevalencia y el curso de numerosos trastornos del estado de ánimo. Los trabajos existentes se han centrado en conocer el papel de la tipología circadiana en el desarrollo y mantenimiento de la patología, así como en la influencia que ésta puede tener en el manejo terapéutico y en el pronóstico de recaídas. 


\section{Trastorno afectivo estacional y depresión mayor}

Una de las manifestaciones clínicas observables durante el curso de un estado depresivo es la alteración de los ritmos circadianos (Germain y Kupfer, 2008). Durante los últimos años diversos estudios han mostrado que tanto en el trastorno afectivo estacional (Natale, Adan y Scapellato, 2005; Wirz-Justice, 2008), como en la depresión mayor (Abe et al., 2011; Wirz-Justice, 2008), se produce un retraso de fase en la expresión rítmica circadiana. Las alteraciones circadianas durante los trastornos afectivos suelen ser evidentes en el ciclo sueño-vigilia (Ford y Cooper-Patrick, 2001), la temperatura corporal y los ritmos hormonales (Crocq, 2008). En esta línea, Wirz-Justice et al. (2004) han observado que intervenciones basadas en la modificación de parámetros circadianos (terapia lumínica y privación de sueño), ocasionando el adelanto de fase en la secreción nocturna de melatonina, se han mostrado eficaces para disminuir la sintomatología depresiva.
A excepción de unos pocos trabajos (Putilov, 2008; Taylor, Clay, Bramoweth, Sethi y Roane, 2011), la mayoría de las investigaciones han hallado asociaciones entre la tipología circadiana y sintomatología depresiva (Abe et al., 2011; Antunes, da Jornada, Ramalho e Hidalgo, 2010; Hidalgo et al., 2009; Hsu, Gau, Shang, Chiu y Lee, 2012; Kitamura et al., 2010; Levandovski et al., 2011; Mecacci y Rocchetti, 1998; Natale et al., 2005; Ong, Huang, Kuo y Manber, 2007; Pabst, Negriff, Dorn, Susman y Huang, 2009; Randler, 2011; Takeuchi, Oishi y Harada, 2005; Tzischinski y Shochat, 2011), así como con depresión mayor (Gaspar-Barba et al., 2009; Meliska et al., 2011; Selvi et al., 2010.). En la Tabla 1 se presentan los principales resultados existentes en el tema. Como puede observarse, la tipología vespertina se asocia a una mayor prevalencia de sintomatología depresiva e ideación suicida, y los síntomas suelen ser más intensos que en los individuos matutinos e intermedios con el mismo diagnóstico.

Tabla 1. Relación entre tipología circadiana y trastornos depresivos.

\begin{tabular}{|c|c|c|c|}
\hline Autores & Muestra & Instrumentos & Resultados \\
\hline $\begin{array}{l}\text { Abe et al. } \\
\text { (2011). }\end{array}$ & $\begin{array}{l}90 \text { pacientes con síndrome } \\
\text { de fase atrasada del sueño. }\end{array}$ & SDS, EES. & $\begin{array}{l}\text { La sintomatología depresiva asociada a los pacientes está más } \\
\text { relacionada con la vespertinidad que con el ciclo sueño-vigilia. }\end{array}$ \\
\hline $\begin{array}{l}\text { Antunes et al. } \\
(2010) \text {. }\end{array}$ & $\begin{array}{l}27 \text { adultos de } 25-60 \text { ( } 14 \text { de } \\
\text { ellos trabajan por turnos). }\end{array}$ & SRQ-20, BDI. & $\begin{array}{l}\text { La vespertinidad se asocia con algunos trastornos del estado de } \\
\text { ánimo. }\end{array}$ \\
\hline $\begin{array}{l}\text { Gaspar-Barba } \\
\text { et al. (2009). }\end{array}$ & $\begin{array}{l}100 \text { pacientes con trastorno } \\
\text { depresivo mayor de } 18-60 \\
\text { años. }\end{array}$ & MEQ, MINI, HRSD. & $\begin{array}{l}\text { La tipología vespertina se asocia con ideación suicida, sintoma- } \\
\text { tología paranoide, ansiedad y deterioro laboral, mientras que la } \\
\text { tipología matutina se relaciona con menor proporción de sinto- } \\
\text { matología melancólica. }\end{array}$ \\
\hline $\begin{array}{l}\text { Hidalgo et al. } \\
\text { (2009). }\end{array}$ & 200 adultos de 18-99 años. & $\begin{array}{l}\text { MADRS, e } \\
\text { esperanza, }\end{array}$ & $\begin{array}{l}\text { ertinidad se asocia a un mayor riesgo de informar de sin- } \\
\text { gía depresiva moderada-severa. }\end{array}$ \\
\hline $\begin{array}{l}\text { Hsu et al. } \\
\text { (2012). }\end{array}$ & $\begin{array}{l}2919 \text { estudiantes de primer } \\
\text { año mayores de edad. }\end{array}$ & M-E Scale, BSRS. & $\begin{array}{l}\text { Los vespertinos presentaron mayores puntuaciones en la subes- } \\
\text { cala de depresión del BSRS que los matutinos. }\end{array}$ \\
\hline $\begin{array}{l}\text { Kitamura et al. } \\
(2010) \text {. }\end{array}$ & 1170 adultos de $20-59$ años. & MEQ, CES-D. & $\begin{array}{l}\text { La tipología vespertina extrema se asocia con un incremento de } \\
\text { la incidencia de los estados depresivos, mientras que la tipología } \\
\text { matutina extrema se asocia con una reducción de la incidencia } \\
\text { de los mismos. }\end{array}$ \\
\hline $\begin{array}{l}\text { Levandovski et } \\
\text { al. (2011). }\end{array}$ & $\begin{array}{l}4051 \text { personas de } 18-65 \\
\text { años. }\end{array}$ & MCTQ, BDI. & $\begin{array}{l}\text { Asociación entre tipología vespertina y sintomatología depresi- } \\
\text { va. Esta relación es más estrecha en individuos de 31-40 años. }\end{array}$ \\
\hline Mecacci y Roc- & 232 universitarios de $20-26$ & MEQ, BDI. & La vespertinidad se asocia a depresión. \\
\hline
\end{tabular}

chetti (1998). años.

Meliska et al. 19 controles normales y 10 MEQ, SIGH-SAD.

(2011). pacientes deprimidos de 46-

72 años (todos mujeres).

Natale et al. 1715 estudiantes universita- MEQ, SPAQ.

(2005). rios de España e Italia de

18-34 años.

Ong et al. $\quad 312$ pacientes del grupo de MECS, BDI.

(2007). terapia cognitivo conductual para el insomnio

Pabst et al. 264 mujeres de 11-17 años. M-E scale, CDI.

(2009).

Putilov (2008). 2240 personas de 18-57 SWPAQ, CES-D. años.

Randler (2011). 307 jóvenes de 10-20 años. CSM, BFWKJ.

Selvi et al. $\quad 80$ individuos durante su MEQ, SCID-I, (2010). $\quad$ primer episodio de depre- PSQI, SIS, MINI. sión mayor y 80 controles
Los síntomas de depresión atípica eran más severos en las mujeres deprimidas vespertinas que en aquellas con tipología matutina.

Mayor incidencia de vespertinidad en los individuos con depresión estacional.

Mayor sintomatología depresiva en vespertinos que en matutinos e intermedios.

La vespertinidad se asocia a mayor sintomatología depresiva, tras el control de la edad, raza y estatus socioeconómico.

Apenas hay diferencias entre matutinos y vespertinos en depresión.

Asociación entre vespertinidad y afecto depresivo antes y después de controlar la edad.

BDI, Asociación entre tipología circadiana e inicio de la depresión mayor, aunque controlando los efectos del sueño y la depresión sin diferencias significativas. Mayor severidad de los síntomas 


\begin{abstract}
sanos.
depresivos e ideación suicida en pacientes vespertinos.

Takeuchi et al. 417 niñas de 12-15 años y MEQ, Cuestionario de Las estudiantes vespertinas se sentían más deprimidas que las (2005). $\quad 252$ jóvenes de 18-31 años. síndrome premenstrual y matutinas. Los cambios de humor y dolores del ciclo menstrual de ciclo menstrual. (grupo de 18-31 años) se asocian a mayor vespertinidad.

Taylor et al. 838 estudiantes menores de MEQ, QIDS. No se encontró relación entre la tipología circadiana y depre(2011). 26 años.

Tzischinsky y 444 adolescentes. SSHS, PedsQL Short La tipología vespertina se asocia más a estado de ánimo depriShochat (2011). Form. $\quad$ mido que la matutina e intermedia.

BDI: Beck Depression Inventory; BFWKJ: Berner Fragebogen zum Wohlbefinden von Kindern und Jugendlichen; BSRS: Brief Symptom Rating Scale; CDI: Children's Depression Inventory; CES-D: Center for Epidemiological Studies-Depression Scale; CSM: Composite Scale of Morningness; ESS: Epworth Sleepiness Scale; HRSD: Hamilton Rating Scale for Depression; M-E Scale: Morningness-Eveningness Scale; MADRS: Montgomery-Äsberg Depression Rating Scale; MCTQ: Munich ChronoType Questionnaire; MEQ: Morningness-Eveningness Questionnaire; MECS: Morningness-Eveningness Composite Scale; MINI: Mini-International Neuropsychiatric Interview; PedsQL: Pediatric Quality of Life Inventory; PSQI: Pittsburgh Sleep Quality Index; QIDS: Quick Inventory of Depressive Symptomatology; SCID-I: Structured Clinical Interview for DSM-IV Axis I Disorders; SDS: Self-rating Depression Scale; SIGH-SAD: Structured Interview Guide for the Hamilton Depression Rating Scale, Seasonal Affective Disorder; SIS: Suicide Ideation Scale; SPAQ: Seasonal Pattern Assessment Questionnaire; SRQ-20: Self Report Questionnaire; SSHS: School Sleep Habits Survey; SWPAQ: Sleep-Wake Pattern Assessment Questionnaire.
\end{abstract}

\section{Trastorno bipolar}

Las alteraciones de los ritmos circadianos son comunes durante el curso del trastorno bipolar I. Diversos estudios han señalado alteraciones en el sueño, la actividad y el apetito, así como en la secreción de hormonas en pacientes con trastorno bipolar I tanto durante la remisión como en la recaída (Kennedy, Kutcher, Ralevski y Brown, 1996; Leibenluft, Albert, Rosenthal y Wehr, 1996; Nurnberger, Berrettini, Simmons-Alling, Lawrence y Brittain, 1990). A partir de estos datos se ha sugerido que las alteraciones en los ritmos circadianos pueden estar involucradas en la patogénesis del trastorno bipolar (Mitterauer, 2000).

Diversos fármacos reguladores del estado de ánimo, entre los que destaca el litio, presentan efectos moduladores en los ritmos circadianos (Abe, Herzog y Block, 2000). Técnicas no farmacológicas destinadas a la modificación de los ritmos circadianos también se han mostrado eficaces en el tratamiento del trastorno bipolar (Anderson, 2010; Wirz-Justice, 2003). Finalmente, se ha observado que los viajes a través de diversas zonas horarias pueden precipitar síntomas depresivos (viajes hacia el oeste) o maníacos (viajes hacia el este) en población con esta problemática (Soreca, Fagiolini, Frank, Goodpaster y Kupfer, 2009).

Como se aprecia en la Tabla 2, los estudios orientados a conocer la relación entre la tipología circadiana y el trastorno bipolar destacan una inclinación hacia la tipología vespertina en los pacientes respecto a individuos sanos que, en ocasiones extremas, puede llegar a ser un síndrome de retraso de fase (Ahn et al., 2008; Giglio et al., 2010; Wood et al., 2009). Cabe matizar que las personas con trastorno bipolar I presentan esta misma tendencia siempre y cuando se controle la edad (Mansour et al., 2005) y que el trastorno bipolar II podría encontrarse más estrechamente relacionado con la vespertinidad que el trastorno bipolar I (Chung et al., 2012).

\section{Esquizofrenia y otros trastornos psicóticos}

Pese a la evidencia de alteraciones circadianas en los individuos afectados de esquizofrenia y otros trastornos psicóticos (ver Tabla 3), el papel de la tipología circadiana en esta población ha sido poco estudiado. En estos pacientes son comunes los problemas del ciclo sueño-vigilia, pudiéndose destacar que suelen estar más tiempo en cama, sufren más interrupciones durante el sueño, duermen más durante el día y su ritmicidad circadiana es menos robusta (Martin, Jeste y Ancoli-Israel, 2005). La termorregulación también se ve alterada en estos individuos, pues presentan una temperatura corporal basal más elevada y un avance horario de los máximos de temperatura que se producen por la mañana (Chong y Castle, 2004). La afectación del eje pituitario adrenal, cuya hiperactividad es común en la esquizofrenia, es otra de las funciones circadianas afectadas en este trastorno (Ryan, Sharifi, Condren y Thakore, 2004).

Algunos estudios han comparado las puntuaciones de matutinidad-vespertinidad de individuos con esquizofrenia o trastorno esquizoafectivo y controles sanos. En los pacientes con trastornos psicóticos no existe relación alguna entre la edad y las puntuaciones de matutinidad-vespertinidad, a diferencia de lo observado en controles sanos (Ahn et al., 2008; Mansour et al., 2005).

\section{Trastornos de la conducta alimentaria}

Los trastornos de la conducta alimentaria aparecen frecuentemente durante la adolescencia y en población femenina (Schmidt y Randler, 2010), y suelen mantenerse pasada esta etapa vital (Natale, Ballardini, Schumann, Mencarelli y Magelli, 2008). Durante los años 90 se inició el estudio de la relación entre los trastornos de la conducta alimentaria y los ritmos biológicos. Se observó que la tendencia a comer durante la noche es más prevalente en aquellas personas que suelen sufrir atracones (Rand, Macgregor y Stunkard, 1997), que las personas bulímicas suelen acostarse y levantarse una hora más tarde que aquellas que no sufren dicha problemática (Latzer, Tzischinsky, Epstein, Klein y Peretz, 1999), que los atracones son más probables durante la noche que durante el día (Johnson, Schlundt, Barclay, Carr-Nangle y Engler, 1995) y que la frecuencia de atracones y purgas se incrementa durante los meses con menos horas de luz solar (Lam, Goldner y Grewal, 1996). 
Tabla 2. Relación entre tipología circadiana y trastorno bipolar.

\begin{tabular}{lll}
\hline Autores & Muestra & Instrumentos \\
\hline Ahn et al. & 92 pacientes con trastorno bipo- & CSM, DSM-IV. \\
$(2008)$. & $\begin{array}{l}\text { lar, } 113 \text { con esquizofrenia y } 95 \\
\text { controles. }\end{array}$ \\
Chung et al. & $\begin{array}{l}106 \text { pacientes con trastorno bipo- } \\
\text { lar I, } 43 \text { con trastorno bipolar II y }\end{array}$ \\
& 108 con depresión mayor.
\end{tabular}

Giglio et al. 81 pacientes con trastorno bipo(2010). lar y 79 controles. SCID, entrevista para la evalua- Los pacientes con trastorno bipolar se encuentran Cion de los ritmos biológicos,
HRSD, YMRS.

Kennedy et 9 pacientes con trastorno bipolar SCID, marcadores biológicos. al. (1996). y 12 controles. $\begin{array}{lll}\text { Leibenluft et } & 11 \text { pacientes con trastorno bipo- } & \text { SCID, registro de sueño y de es- La disminución del tiempo de sueño es el mejor } \\ \text { al. (1996). } & \text { lar con ciclos rápidos. } & \text { tado de ánimo. }\end{array}$ Mansour et al. 349 controles, 70 pacientes con CSM, DIGS. (2005). trastorno bipolar I, 39 con esquizofrenia y 42 con trastorno esquizoafectivo.

Nurnberger et 14 controles, 8 bipolar I y 3 bipo- Radioinmunoensayo, cromatogra- Los niveles de cortisol y ACTH de los pacientes al. (1990). lar II. fía líquida de alta resolución con con trastorno bipolar son menos sensibles a la addetección electroquímica. ministración de triptófano en comparación con los controles.

Soreca et al. 29 pacientes con trastorno bipo- CSM, SCID, HRSD, YMRS, La tipología circadiana explica el 19\% de la grasa (2009). lar I (18-60 años). LIFE, PSQI, DXA. corporal tras los factores edad, sexo, estado de ániWood et al. 190 pacientes con trastorno bipo- CSM, SCID, K-SADS-PL, BDI. $\quad \begin{aligned} & \text { mo y calidad del sueño. } \\ & \text { Puntuaciones superiores de vespertinidad en los pa- }\end{aligned}$ (2009). lar y 128 controles. Puntuaciones superiores de vespertinidad en los pa-
cientes con trastorno bipolar. BDI: Beck Depression Inventory; CSM: Composite Scale of Morningness; DIGS: Diagnostic Interview for Genetic Studies; DXA: Dual x-ray absorptiometry; HRSD: Hamilton Rating Scale for Depression; K-MINI: Korean version of Mini International Neuropsychiatric Interview; K-SADS-PL: Kiddie-SadsPresent and Lifetime; LIFE: Longitudinal Interval Follow-up Evaluation; PSQI: Pittsburgh Sleep Quality Index; SCID: Structured Clinical Interview for DSM; YMRS: Young Mania Rating Scale.

Tabla 3. Relación entre tipología circadiana y trastornos psicóticos.

\begin{tabular}{|c|c|c|c|}
\hline Autores & Muestra & Instrumentos & Resultados \\
\hline $\begin{array}{l}\text { Ahn et al. } \\
(2008) \text {. }\end{array}$ & $\begin{array}{l}92 \text { pacientes con trastorno bipolar, } 113 \text { con } \\
\text { esquizofrenia y } 95 \text { controles. }\end{array}$ & CSM, DSM-IV. & $\begin{array}{l}\text { No se observan diferencias en tipología circadiana entre } \\
\text { los tres grupos. No hay asociación entre tipología circa- } \\
\text { diana y edad en pacientes con esquizofrenia. }\end{array}$ \\
\hline $\begin{array}{l}\text { Mansour et } \\
\text { al. (2005). }\end{array}$ & $\begin{array}{l}349 \text { controles, } 70 \text { pacientes con trastorno } \\
\text { bipolar I, } 39 \text { con esquizofrenia y } 42 \text { con } \\
\text { trastorno esquizoafectivo. }\end{array}$ & CSM, DIGS. & $\begin{array}{l}\text { Los pacientes con esquizofrenia y trastorno esquizoafec- } \\
\text { tivo mostraron puntuaciones más vespertinas en compa- } \\
\text { ración con los controles, ajustando la edad. }\end{array}$ \\
\hline $\begin{array}{l}\text { Martin et al. } \\
(2005) \text {. }\end{array}$ & $\begin{array}{l}28 \text { pacientes con esquizofrenia y } 28 \text { contro- } \\
\text { les. }\end{array}$ & SCID, Actigrafía. & $\begin{array}{l}\text { Los ancianos con esquizofrenia sufren mayores proble- } \\
\text { mas circadianos y de sueño que los controles. }\end{array}$ \\
\hline $\begin{array}{l}\text { Ryan et al. } \\
\text { (2004). }\end{array}$ & $\begin{array}{l}12 \text { pacientes con esquizofrenia y } 12 \text { contro- } \\
\text { les }\end{array}$ & $\begin{array}{l}\text { Marcadores hormo- } \\
\text { nales y DSM-IV. }\end{array}$ & $\begin{array}{l}\text { En el primer episodio de esquizofrenia sin tratamiento } \\
\text { farmacológico se observa hiperactividad basal en el eje } \\
\text { pituitario-adrenal. }\end{array}$ \\
\hline
\end{tabular}

Kasof (2001) encontró que la vespertinidad se hallaba, aunque de forma moderada, directamente relacionada con dos medidas de conducta bulímica: The Bulimia Scale of the Eating Disorders Inventory y The Bulimia Test Revised. Posteriormente, Natale et al. (2008) no evidenciaron una asociación significativa entre tipología circadiana y bulimia, pero sí observaron que la proporción de vespertinos en el grupo clínico doblaba a la del grupo control. Además, la aplicación de un tratamiento eficaz producía una remisión de la sintomatología seguida de un aumento en las puntuaciones de matu- tinidad. Paralelamente, Schubert y Randler (2008) constataron una relación positiva entre matutinidad y restricción alimentaria (conducta habitual en personas con anorexia nerviosa), y una relación negativa entre matutinidad con alimentación descontrolada, hambre percibida e índice de masa corporal (comportamiento habitual en los individuos con problemas de bulimia). Más recientemente, Schmidt y Randler (2010) hallaron una correlación positiva entre la insatisfacción corporal y la delgadez con el horario de sueño. Concretamente, encontraron una interrelación entre el índice de 
masa corporal, la edad y el continuo matutinidadvespertinidad, de modo que las niñas más mayores presentaban un mayor índice de masa corporal y mayor vespertini- dad. En la Tabla 4 se muestran los principales resultados de los artículos analizados.

Tabla 4. Relación entre tipología circadiana y trastornos de la conducta alimentaria.

\begin{tabular}{|c|c|c|c|}
\hline Autores & Muestra & Instrumentos & Resultados \\
\hline $\begin{array}{l}\text { Johnson et } \\
\text { al. (1995). }\end{array}$ & $\begin{array}{l}70 \text { mujeres ( } 25 \text { con trastorno por } \\
\text { atracones, } 19 \text { con atracones o ali- } \\
\text { mentación compulsiva no clínica y } \\
26 \text { controles). }\end{array}$ & QEWP, SMAS. & $\begin{array}{l}\text { Los atracones son más probables durante la noche, es- } \\
\text { pecialmente durante la cena o con snacks tras la misma. }\end{array}$ \\
\hline $\begin{array}{l}\text { Kasof } \\
\text { (2001). }\end{array}$ & 151 estudiantes. & $\begin{array}{l}\text { CSM, Bulimia Scale of the } \\
\text { Eating Disorders Inventory, } \\
\text { BULIT-R, EDI-2 }\end{array}$ & $\begin{array}{l}\text { La vespertinidad correlaciona positivamente con medi- } \\
\text { das de conducta bulímica. }\end{array}$ \\
\hline $\begin{array}{l}\text { Lam et al. } \\
\text { (1996). }\end{array}$ & $\begin{array}{l}141 \text { mujeres ( } 60 \text { con bulimia, } 31 \text { con } \\
\text { anorexia y } 50 \text { controles). }\end{array}$ & SPAQ, DSM-III-R. & $\begin{array}{l}\text { Los síntomas de la bulimia nerviosa siguen un patrón } \\
\text { estacional, los atracones y purgas aumentan los meses } \\
\text { con menos horas de luz. }\end{array}$ \\
\hline $\begin{array}{l}\text { Latzer et al. } \\
(1999) \text {. }\end{array}$ & $\begin{array}{l}46 \text { mujeres ( } 25 \text { con bulimia y } 21 \text { con- } \\
\text { troles). }\end{array}$ & Actigrafía, MSQ y STCS. & $\begin{array}{l}\text { Las pacientes con bulimia se acuestan y levantan una } \\
\text { hora más tarde que las del grupo control. }\end{array}$ \\
\hline $\begin{array}{l}\text { Natale et al. } \\
\text { (2008). }\end{array}$ & $\begin{array}{l}270 \text { mujeres (146 con TCA y } 124 \\
\text { controles). }\end{array}$ & rMEQ, EDI-2. & $\begin{array}{l}\text { Mayor proporción de vespertinidad en el grupo con } \\
\text { TCA. El tratamiento de los TCA incrementa las pun- } \\
\text { tuaciones en el rMEQ y reduce la sintomatología eva- } \\
\text { luada mediante el EDI- } 2 \text {. }\end{array}$ \\
\hline $\begin{array}{l}\text { Schmidt y } \\
\text { Randler } \\
\text { (2010). }\end{array}$ & 284 adolescentes de 12-17 años. & CSM, EDI-2. & $\begin{array}{l}\text { A mayor vespertinidad puntuaciones superiores en la } \\
\text { escala de TCA. Asociación entre índice de masa corpo- } \\
\text { ral y matutinidad. }\end{array}$ \\
\hline $\begin{array}{l}\text { Schubert y } \\
\text { Randler } \\
\text { (2008). }\end{array}$ & 352 estudiantes. & CSM, TFEQ. & $\begin{array}{l}\text { Los matutinos son más proclives a la restricción ali- } \\
\text { mentaria. A mayor vespertinidad mayor desinhibición y } \\
\text { hambre percibida. }\end{array}$ \\
\hline
\end{tabular}

BULIT-R: Bulimia Test-Revised; CSM: Composite Scale of Morningness; EDI-2: Second edition of the Eating Disorder Inventory; MSQ: Mini-Sleep Questionnaire; QEWP: Questionnaire of Eating and Weight Patterns; rMEQ: reduced Morningness-Eveningness Questionnaire; SMAS: Self-Monitoring Analysis System; SPAQ: Seasonal Pattern Assessment Questionnaire; STCS: Standard Technion Clinical Sleep questionnaire; TCA: Trastornos de la conducta alimentaria; TFEQ: Three-Factor-Eating-Questionnaire.

\section{Trastornos del sueño}

La tipología circadiana también parece hallarse implicada en el desarrollo y mantenimiento de alteraciones del ciclo sueño-vigilia (ver Tabla 5). Se ha observado que los individuos vespertinos manifiestan mayores niveles de somnolencia diurna y poseen creencias más inapropiadas sobre el sueño que los matutinos (Adan, Fabbri, Natale y Prat, 2006; Hidalgo, de Souza, Zanette y Nunes, 2003). Éstos, además, pasan más tiempo en la cama y duermen más que los matutinos e intermedios, pudiendo ser ello una estrategia eficaz para compensar la falta de sueño nocturno (Ong et al., 2007).

Estudios realizados en personas con insomnio han mostrado un retraso en los patrones de la temperatura corporal central, en casos de insomnio de inicio, así como un adelanto en los patrones de la misma en los individuos que presentan insomnio caracterizado por el despertar temprano (Lack y Wright, 1993; Morris, Lack y Dawson, 1990). Estos datos sugieren un importante papel de los ritmos circadianos en la patogénesis del insomnio. Ong et al. (2007) encontraron que los individuos vespertinos, que presentan una mayor preocupación que los matutinos por las consecuencias del in- somnio, se quejaban de una mayor cantidad de sintomatología asociada al insomnio que los matutinos. En esta línea, Fernández-Mendoza et al. (2009) observaron una mayor prevalencia de vespertinos en una muestra de pacientes con insomnio respecto a los controles sanos.

Los individuos vespertinos que tienden a incrementar el tiempo de sueño los fines de semana y a dormir la siesta entre semana (Hidalgo et al., 2003; Ong et al., 2007; Tzischinsky y Shochat, 2011), así como a acostarse y levantarse unas dos horas más tarde que los matutinos, podrían presentar una mayor necesidad de sueño (Meliska et al., 2011). Esto podría explicar la mayor prevalencia de individuos vespertinos en una muestra de personas con hipersomnia idiopática (Vernet y Arnulf, 2009).

Otra de las diferencias halladas se observa en la respuesta al incremento de presión homeostática durante el sueño, más pronunciada en matutinos que en vespertinos y reflejada mediante una mayor presencia de actividad de ondas lentas (Mongrain y Dumont, 2007). También se ha observado que los vespertinos presentan menos dificultades que los matutinos para adaptarse a los cambios en los hábitos de sueñovigilia (Natale, Martoni y Cicogna, 2003), por lo que pueden tolerar mejor el trabajo por turnos. 
Tabla 5. Relación entre tipología circadiana y trastornos del sueño.

\begin{tabular}{|c|c|c|c|}
\hline Autores & Muestra & Instrumentos & Resultados \\
\hline $\begin{array}{l}\text { Adan et al. } \\
\text { (2006). }\end{array}$ & $\begin{array}{l}510 \text { estudiantes de } 18- \\
\text { 33años. }\end{array}$ & rMEQ, SBS. & $\begin{array}{l}\text { Los matutinos presentan mayores puntuaciones que los vespertinos } \\
\text { en la SBS. }\end{array}$ \\
\hline Fernández- & 1238 estudiantes de $16-$ & MEQ, cuestionario de & La tipología vespertina se encuentra estrechamente relacionada con \\
\hline $\begin{array}{l}\text { Mendoza et al. } \\
(2009) \text {. }\end{array}$ & 25 años. & $\begin{array}{l}\text { hábitos y problemas de } \\
\text { sueño, ESS. }\end{array}$ & problemas de insomnio. \\
\hline $\begin{array}{l}\text { Hidalgo et al. } \\
(2003) \text {. }\end{array}$ & $\begin{array}{l}310 \text { estudiantes univer- } \\
\text { sitarios. }\end{array}$ & MEQ, ESS. & $\begin{array}{l}\text { Los vespertinos presentan mayores niveles de somnolencia diurna } \\
\text { que los matutinos. }\end{array}$ \\
\hline $\begin{array}{l}\text { Lack y Wright } \\
\text { (1993). }\end{array}$ & $\begin{array}{l}9 \text { participantes de } 32- \\
77 \text { años. }\end{array}$ & $\begin{array}{l}\text { Cuestionario y diario de } \\
\text { sueño, actigrafía. }\end{array}$ & $\begin{array}{l}\text { El insomnio de inicio se caracteriza por un retraso de fase del ritmo } \\
\text { circadiano (vespertinidad) y el de despertar temprano por un adelanto } \\
\text { en ello. }\end{array}$ \\
\hline $\begin{array}{l}\text { Natale et al. } \\
\text { (2003). }\end{array}$ & $\begin{array}{l}18 \text { controladores aé- } \\
\text { reos. }\end{array}$ & CSM, actigrafía. & $\begin{array}{l}\text { Los vespertinos presentan hábitos más flexibles de sueño y duermen } \\
\text { menos que los matutinos. }\end{array}$ \\
\hline $\begin{array}{l}\text { Meliska et al. } \\
\text { (2011). }\end{array}$ & $\begin{array}{l}19 \text { controles y } 10 \text { per- } \\
\text { sonas con depresión de } \\
46-72 \text { años. }\end{array}$ & $\begin{array}{l}\text { MEQ, Marcadores bio- } \\
\text { lógicos, PSG. }\end{array}$ & $\begin{array}{l}\text { Las mujeres vespertinas presentan un retraso de fase en la liberación } \\
\text { de melatonina en comparación a las matutinas. }\end{array}$ \\
\hline $\begin{array}{l}\text { Mongrain y } \\
\text { Dumont (2007). }\end{array}$ & $\begin{array}{l}24 \text { adultos de } 19-34 \\
\text { años. }\end{array}$ & MEQ, PSG. & $\begin{array}{l}\text { Los matutinos muestran mayor respuesta que los vespertinos a los } \\
\text { incrementos de presión homeostática durante el sueño. }\end{array}$ \\
\hline $\begin{array}{l}\text { Morris et al. } \\
(1990) \text {. }\end{array}$ & $\begin{array}{l}22 \text { participantes }(13 \\
\text { con insomnio de inicio } \\
\text { y } 9 \text { controles). }\end{array}$ & PSG. & $\begin{array}{l}\text { El ritmo de la temperatura corporal de las personas con insomnio de } \\
\text { inicio se encuentra retrasado en comparación con los controles. }\end{array}$ \\
\hline $\begin{array}{l}\text { Ong et al. } \\
(2007) \text {. }\end{array}$ & $\begin{array}{l}312 \text { pacientes con in- } \\
\text { somnio. }\end{array}$ & $\begin{array}{l}\text { MECS, diario de sueño, } \\
\text { DBAS. }\end{array}$ & $\begin{array}{l}\text { Los vespertinos muestran mayor tiempo total de sueño, mayor tiem- } \\
\text { po en cama, mayor variabilidad en el tiempo fuera de la cama y ma- } \\
\text { yores niveles de distrés que matutinos e intermedios. }\end{array}$ \\
\hline $\begin{array}{l}\text { Tzischinsky y } \\
\text { Shochat (2011). }\end{array}$ & 444 adolescentes. & $\begin{array}{l}\text { SSHS, PedsQL Short } \\
\text { Form. }\end{array}$ & $\begin{array}{l}\text { Los vespertinos presentan entre semana menor funcionamiento dia- } \\
\text { rio, se acuestan más tarde, tienen mayor latencia de sueño y duermen } \\
\text { menos que los matutinos e intermedios. Los fines de semana los ves- } \\
\text { pertinos presentan mayor cantidad de tiempo total de sueño. }\end{array}$ \\
\hline $\begin{array}{l}\text { Vernet y Arnulf } \\
(2009) \text {. }\end{array}$ & $\begin{array}{l}30 \text { controles y } 75 \text { pa- } \\
\text { cientes con insomnio } \\
\text { idiopático. }\end{array}$ & PSG, MSLT. & $\begin{array}{l}\text { La hipersomnia se asocia a la tipología vespertina, especialmente en } \\
\text { personas jóvenes. }\end{array}$ \\
\hline
\end{tabular}

CSM: Composite Scale of Morningness; DBAS: Dysfunctional Beliefs and Attitudes about Sleep; ESS: Epworth Sleepiness Scale; MECS: MorningnessEveningness Composite Scale; MEQ: Morningness-Eveningness Questionnaire; MLST: Multiple Sleep Latency Test; PedsQL: Pediatric Quality of Life Inventory; PSG: Polisomnografía; rMEQ: reduced Morningness-Eveningness Questionnaire; SBS: Sleep Beliefs Scale; SSHS: School Sleep Habits Survey.

\section{Consumo, abuso y dependencia de sustancias}

Diversos estudios han mostrado que el consumo de drogas conlleva efectos negativos sobre la expresión rítmica circadiana. De hecho, las personas con problemas de abuso y/o dependencia de sustancias suelen presentar un aplanamiento de la amplitud de las funciones circadianas y un retraso horario de los valores máximos, pudiéndose producir incluso un estado de desincronización del control endógeno (Adan, 2010; Conroy et al., 2012; Hasler, Smith, Cousins y Bootzin, 2012). Esta alteración de la ritmicidad circadiana deriva en dificultades de adaptación a los cambios ambientales y se asociaría con un amplio rango de alteraciones.

Adan (1994), en un estudio pionero, observó un mayor consumo de drogas legales (alcohol, nicotina y cafeína) en vespertinos respecto a matutinos e intermedios. Recientemente, Urbán, Magyaródi y Rigó (2011) y Taylor et al. (2011) han evidenciado que el consumo de alcohol a lo largo de la vida es superior en los vespertinos, y Prat y Adan (2011) han hallado que los vespertinos también consumen más drogas ilegales (cannabis, éxtasis, cocaína), presentan más problemas relacionados con el consumo de alcohol y una mayor severidad en los síntomas de resaca (dificultades de aprendi- zaje, cansancio, dolores de cabeza, hipersensibilidad sensorial, ansiedad, irritabilidad y sed) que los matutinos.

Por otro lado, se ha observado que los fumadores jóvenes presentan una menor amplitud y un retraso horario del máximo en los valores diurnos de activación subjetiva y del estado afectivo, en comparación con no fumadores (Adan y Sánchez-Turet, 2000), siendo ello más marcado en los de dependencia alta (Adan, Prat y Sánchez-Turet, 2004). En esta línea, los fumadores presentan una marcada tendencia hacia la vespertinidad, así como grandes diferencias a la hora de levantarse de lunes a viernes respecto a los fines de semana (Randler, 2008b; Urbán et al., 2011). También en consumidores crónicos de alcohol es común la presencia de un aplanamiento de la amplitud rítmica tanto de la temperatura corporal como de la melatonina, situación que se vería potenciada por el síndrome de abstinencia (Adan, 2010). Aunque la mayoría de trabajos se han realizado con alcohol y tabaco, la afectación de la ritmicidad circadiana con el consumo continuado de drogas parece generalizable a todas ellas (Adan, 2013). En la Tabla 6 se muestran los principales resultados existentes sobre consumo de drogas y tipología circadiana. 
Tabla 6. Relación entre tipología circadiana y consumo de drogas.

\begin{tabular}{|c|c|c|c|}
\hline Autores & Muestra & Instrumentos & Resultados \\
\hline Adan (1994). & $\begin{array}{l}537 \text { participantes de } 21- \\
30 \text { años. }\end{array}$ & rMEQ, entrevista. & $\begin{array}{l}\text { Los individuos vespertinos consumen más alcohol, nicotina y cafeína(café y } \\
\text { bebidas de cola), mientras que los matutinos consumen más cafeína prove- } \\
\text { niente del té. }\end{array}$ \\
\hline $\begin{array}{l}\text { Adan et al. } \\
(2004) \text {. }\end{array}$ & $\begin{array}{l}60 \text { estudiantes (40 fu- } \\
\text { madores y } 20 \text { no fuma- } \\
\text { dores) de } 16-26 \text { años. }\end{array}$ & $\begin{array}{l}\text { rMEQ, FTND, escala } \\
\text { de activación y de es- } \\
\text { tado de ánimo. }\end{array}$ & $\begin{array}{l}\text { Las funciones diurnas de activación y estado de ánimo de los fumadores con } \\
\text { alta dependencia se encuentran más afectadas durante las primeras horas del } \\
\text { día mientras que la baja dependencia se asocia a un mayor impacto de la de- } \\
\text { presión post-pandrial. }\end{array}$ \\
\hline $\begin{array}{l}\text { Prat y Adan } \\
\text { (2011). }\end{array}$ & $\begin{array}{l}517 \text { estudiantes de } 17- \\
30 \text { años. }\end{array}$ & $\begin{array}{l}\text { CSM, AUDIT, cues- } \\
\text { tionario de síntomas } \\
\text { de resaca y consumo } \\
\text { de drogas. }\end{array}$ & $\begin{array}{l}\text { Mayor prevalencia de consumo de sustancias adictivas legales (nicotina y be- } \\
\text { bidas de cola) e ilegales (cannabis y éxtasis), así como mayor puntuación en el } \\
\text { AUDIT y más frecuencia de síntomas de resaca en los vespertinos, en com- } \\
\text { paración con matutinos e intermedios. }\end{array}$ \\
\hline $\begin{array}{l}\text { Randler } \\
\text { (2008b). }\end{array}$ & $\begin{array}{l}326 \text { estudiantes de } 18- \\
49 \text { años. }\end{array}$ & $\begin{array}{l}\text { CSM, entrevista ad- } \\
\text { hoc. }\end{array}$ & $\begin{array}{l}\text { Los fumadores consumen más café y alcohol y presentan una mayor tenden- } \\
\text { cia hacia la vespertinidad, lo que da lugar a mayores diferencias en el horario } \\
\text { de levantarse entre los fines de semana y los días de entre semana. }\end{array}$ \\
\hline $\begin{array}{l}\text { Taylor et al. } \\
\text { (2011). }\end{array}$ & $\begin{array}{l}838 \text { estudiantes de } 17- \\
26 \text { años. }\end{array}$ & MEQ, AUDIT. & $\begin{array}{l}\text { La tipología vespertina se asocia a un mayor consumo de alcohol y cafeína } \\
\text { que la matutina e intermedia. }\end{array}$ \\
\hline $\begin{array}{l}\text { Urbán et al. } \\
\text { (2011). }\end{array}$ & 2565 niños. & $\begin{array}{l}\text { rMEQ, Youth Risk } \\
\text { Behavior Survey. }\end{array}$ & $\begin{array}{l}\text { La tendencia hacia la matutinidad se asocia a una menor probabilidad de con- } \\
\text { sumo de alcohol y tabaco. }\end{array}$ \\
\hline
\end{tabular}

AUDIT: Alcohol Use Disorders Identification Test; CSM: Composite Scale of Morningness; MEQ: Morningness-Eveningness Questionnaire; FTND: Fagerstrom Test for Nicotine Dependence; rMEQ: reduced Morningness-Eveningness Questionnaire.

\section{Ansiedad y Trastorno por déficit de atención con hiperactividad}

\section{Ansiedad}

La investigación sobre tipología circadiana y ansiedad realizada hasta la fecha sólo explora la presencia de niveles de ansiedad (como estado o rasgo, con manifestaciones psicológicas o somáticas) sin haber estudiado trastornos de ansiedad como entidades diagnósticas (Tabla 7). Aunque algunos trabajos no han encontrado relación entre la tipología circadiana y la ansiedad (Kantermann, Theadom, Roen- neberg y Cropley, 2012; Taylor et al., 2011), otros sí han hallado datos que asocian la tipología vespertina con elevados niveles de ansiedad (Díaz-Morales y Sánchez-López, 2008; Gaspar-Barba et al., 2009; Hsu et al., 2012; Mecacci y Rocchetti, 1998), relación que parece potenciarse en mujeres (Díaz-Morales y Sánchez-López, 2008). Asimismo, también se ha propuesto una curva de niveles de ansiedad diferente para matutinos y vespertinos. Los primeros se irían sintiendo más ansiosos con el avance de la tarde y noche, mientras que los segundos sufrirían mayores niveles de ansiedad durante las primeras horas del día (Arushanyan, Mastyagina, Mastyagin y Popova, 2005).

Tabla 7. Relación entre tipología circadiana y ansiedad.

\begin{tabular}{|c|c|c|c|}
\hline Autores & Muestra & Instrumentos & Resultados \\
\hline $\begin{array}{l}\text { Arushanyan et al. } \\
\text { (2005). }\end{array}$ & $\begin{array}{l}86 \text { participantes de } \\
18-23 \text { años. }\end{array}$ & MEQ, STAI. & $\begin{array}{l}\text { Los matutinos presentan mayores niveles de ansiedad a finales del día y } \\
\text { los vespertinos durante las primeras horas del día. }\end{array}$ \\
\hline $\begin{array}{l}\text { Díaz-Morales y Sán- } \\
\text { chez-López (2008). }\end{array}$ & $\begin{array}{l}559 \text { adultos de } 40-63 \\
\text { años. }\end{array}$ & CSM, ERA. & $\begin{array}{l}\text { Correlación negativa entre matutinidad y ansiedad sólo en mujeres. La } \\
\text { vespertinidad, controlando las características sociodemográficas, es uno } \\
\text { de los predictores de ansiedad en ambos sexos. }\end{array}$ \\
\hline $\begin{array}{l}\text { Gaspar-Barba et al. } \\
(2009) \text {. }\end{array}$ & $\begin{array}{l}100 \text { pacientes con de- } \\
\text { presión de } 18-60 \\
\text { años. }\end{array}$ & MEQ, HRSD. & $\begin{array}{l}\text { Los vespertinos presentaron mayores puntuaciones en el "cluster" de an- } \\
\text { siedad de la HRSD que los matutinos. }\end{array}$ \\
\hline Hsu et al. (2012). & 2919 estudiantes. & M-E Scale, BSRS. & $\begin{array}{l}\text { Los vespertinos presentan mayores niveles de ansiedad no fóbica que los } \\
\text { matutinos. }\end{array}$ \\
\hline $\begin{array}{l}\text { Kantermann et al. } \\
\text { (2012). }\end{array}$ & $\begin{array}{l}1548 \text { personas con fi- } \\
\text { bromialgia. }\end{array}$ & $\begin{array}{l}\text { MCTQ FIQR, } \\
\text { HADS. }\end{array}$ & No hay relación entre tipología circadiana y ansiedad. \\
\hline $\begin{array}{l}\text { Mecacci y Rocchetti } \\
\text { (1998). }\end{array}$ & $\begin{array}{l}232 \text { estudiantes de } 20 \text { - } \\
26 \text { años. }\end{array}$ & MEQ, MHQ. & $\begin{array}{l}\text { Los vespertinos presentan mayores niveles de ansiedad que los matuti- } \\
\text { nos. }\end{array}$ \\
\hline Taylor et al. (2011). & $\begin{array}{l}838 \text { estudiantes de } 17- \\
26 \text { años. }\end{array}$ & MEQ, STAI. & No hay relación entre tipología circadiana y ansiedad. \\
\hline
\end{tabular}

BSRS: Brief Symptom Rating Scale; CSM: Composite Scale of Morningness; ERA: Escala Reducida de Ansiedad; FIQR: Fibromyalgia Impact Questionnaire; HADS: Hospital Anxiety and Depression Scale; HRSD: Hamilton Rating Scale for Depression; M-E Scale: Morningness-Eveningness Scale; MCTQ: Munich ChronoType Questionnaire; MEQ: Morningness-Eveningness Questionnaire; MHQ: Middlesex Hospital Questionnaire; STAI: State-Trait Anxiety Inventory. 
Trastorno de déficit de atención con hiperactividad (TDAH)

El TDAH también ha sido objeto de estudio, dadas las similitudes entre los problemas de sueño que sufren estos individuos y las características de las personas vespertinas: mayor latencia de sueño, se acuestan más tarde, conductas impulsivas y dificultades para conciliar el sueño (Caci, Bouchez y Baylé, 2009). En los trabajos analizados (ver Tabla 8) se observa una mayor vespertinidad en adultos con TDAH, en comparación con quienes no presentan el trastorno (Caci, Bouchez y Baylé, 2009; Rybak, McNeely, Mackenzie, Jain y Levitan, 2007; Voinescu, Szentagotai y David, 2012). Además, la vespertinidad se encontraría más asociada a los síntomas de inatención que a la sintomatología hiperactiva (Rybak et al., 2007).

Tabla 8. Relación entre tipología circadiana y TDAH.

\begin{tabular}{|c|c|c|c|}
\hline Autores & Muestra & Instrumentos & Resultados \\
\hline $\begin{array}{l}\text { Caci, Bouchez } \\
\text { y Baylé (2009). }\end{array}$ & 205 adultos. & CSM, ASRS. & $\begin{array}{l}\text { Los adultos con probable TDAH se encuentran más orienta- } \\
\text { dos hacia la vespertinidad. La vespertinidad se relaciona más }\end{array}$ \\
\hline
\end{tabular}
y Baylé (2009). (2007). TDAH de 20-60 SCID, CPT-II, TMT, NAART, sintomatología TDAH y a déficits neuropsicológicos. años. COWAT, WCST, HVLT, JLO.

Voinescu et al. 551 participantes. CSM, ASRS, BAARS-IV, SDQ, SCI, Los individuos con problemas de insomnio y/o TDAH se en(2012). STQ. cuentran más orientados hacia la vespertinidad que los controles. La inatención se asocia a insomnio y vespertinidad.

ASRS: Adult Self-Report Scale for ADHD; BAADD: Brown Adult Attention Deficit Disorder; BAARS-IV: Barkley Adult ADHD Rating Scale-IV; CAARS: Conners Adult ADHD Rating Scale; COWAT: Controlled Oral Word Association Test; CSM: Composite Scale of Morningness; CPT-II: Conners Continuous Performance Test; HVLT: Hopkins Verbal Learning Test; JLO: Judgment of Line Orientation test; MEQ: Morningness-Eveningness Questionnaire; NAART: North American Adult Reading Test; SCI: Sleep Condition Indicator; SCID: Structured Clinical Interview for DSM; SDQ: Sleep Disorders Questionnaire; STQ: Sleep Timing Questionnaire; TMT: Trail Making Test; WCST: Wisconsin Card Sorting Test; WURS: Wender Utah Rating Scale.

\section{Discusión}

Este es el primer trabajo de revisión realizado sobre tipología circadiana y problemas de salud mental. La mayoría de los estudios analizados señalan la existencia de relaciones entre la tipología circadiana (vespertina principalmente) y diversos trastornos mentales como depresión y trastorno afectivo estacional, trastorno bipolar, trastornos de la conducta alimentaria, trastornos del sueño, trastornos por uso de sustancias, y TDAH, así como con elevados niveles de ansiedad. En línea con la hipótesis planteada, la mayoría de resultados sugieren la existencia de vulnerabilidad a desarrollar problemas de salud mental en la tipología vespertina, mientras que la tipología matutina parece actuar como un factor de protección frente al desarrollo de los mismos. La tipología intermedia, por su parte, no ha sido estudiada tan exhaustivamente pero los datos existentes apuntan a que no siempre se sitúa en una posición intermedia entre los extremos matutino y vespertino.

Las relaciones existentes entre la tipología circadiana y los diversos problemas de salud mental analizados apuntan a una implicación de la tipología circadiana en el inicio, curso, remisión y recaída de dichas alteraciones, por lo que ésta debería tenerse en cuenta en la evaluación y tratamiento de pacientes, así como en la prevención de estos problemas en población de riesgo. La terapia cronobiológica (hábitos conductuales, terapia lumínica o terapia farmacológica con melatonina) se postula como una novedosa herramienta que puede resultar de gran utilidad en el tratamiento de diversos problemas de salud mental tales como el trastorno por uso de sustancias y los trastornos de ansiedad (Adan, 2013), trastornos del estado de ánimo (Anderson, 2010; Quera-Salva et al., 2011; Wirz-Justice, 2003; Wirz-Justice et al., 2005), TDAH (Rybak, McNeely, Mackenzie, Jain y Levitan, 2006), problemas de sueño (Gammack, 2008; Kledzik y Thome, 2011) y esquizofrenia (Kledzik y Thome, 2011), si bien se requieren estudios con muestras amplias de sujetos que permitan desarrollar recomendaciones de consenso.

A la hora de buscar teorías explicativas de la relación existente entre el cronotipo y la salud mental destacan tres factores: la genética, el jet lag social y las características y rasgos de personalidad. La tipología circadiana presenta una base genética responsable de, aproximadamente, un 50\% de su variabilidad (Barclay, Eley, Buysse, Archer y Gregory, 2010; Koskenvuo, Hublin, Partinen, Heikkilä y Kaprio, 2007). Varios estudios han encontrado asociaciones entre la tipología circadiana y polimorfismos de los genes reloj Per1 (Carpen, von Schantz, Smits, Skene y Archer, 2006) Per2 (Matsuo, Shiino, Yamada, Ozeki y Okawa, 2007), Per3 (Jones et al., 2007) y Clock (Mishima, Tozawa, Satoh, Saitoh y Mishima, 2005). Genes reloj que también se hallan implicados en diversos problemas de salud mental. En los trastornos depresivos existen asociaciones con polimorfismos en los genes Per2 (Lavebratt, Sjöholm, Partonen, Schalling y Forsell, 2010), Per3 (Nievergelt et al., 2006) y Clock (Benedetti et al., 2003), en el trastorno bipolar destacan los polimorfismos en los genes Per3 (Nievergelt et al., 2006) y Clock (Soria et al., 2010), en el consumo de drogas se han hallado relaciones con los genes Per1 (Liu et al., 2007; McClung, 2007), Per2 (Perreau-Lenz, Zghould, de Fonseca, Spanagel y Bilbao, 2009) y Clock (McClung, Sidiripoulou, Vitaterna, Takahashi y White, 2005), y la esquizofrenia se ha visto asociada a polimorfismos de los genes Per3 (Mansour et al., 2006) y Clock (Zhang et al., 2011). Por último, los trastornos de sueño se 
han relacionado con mutaciones en los genes Per2 y Per3 (Cermakian y Boivin, 2003) y el TDAH con mutaciones en el gen Per2 (Baird, Coogan, Siddiqui, Donev y Thome, 2012).

El jet lag social es un fenómeno descrito como la desincronización entre el reloj social y el biológico, con importantes diferencias horarias entre los días laborales y los festivos (Wittmann, Dinich, Merrow y Roenneberg, 2006). En esta línea, los individuos desarrollarían diferentes patrones conductuales a fin de adaptarse a las demandas socio-culturales, orientadas hacia la matutinidad. Mientras que los individuos matutinos no tendrían grandes dificultades para adaptarse, los vespertinos tendrían que poner en marcha una serie de mecanismos que les permitieran seguir el ritmo y acabar con los efectos perniciosos del jet lag social (v.g. somnolencia). De este modo, los vespertinos tendrían que sobreponerse a dificultades añadidas para adaptarse a los horarios sociales, lo que podría incrementar el riesgo a desarrollar diversas alteraciones: sintomatología afectiva (Wittmann et al., 2006) y ansiosa (Díaz-Morales y Sánchez-López, 2008), problemas de sueño (Giannotti, Cortesi, Sebastiani y Ottaviano, 2002) y consumo de drogas (Adan, 2013).

Las características y rasgos de personalidad, por su parte, se han consolidado como otro factor que podría influir en la relación entre la salud mental y la tipología circadiana. Mientras la asociación existente entre neuroticismo y tipología vespertina podría actuar como factor de vulnerabilidad para el desarrollo de sintomatología depresiva y bipolar (Tonetti et al., 2009), la relación entre búsqueda de sensaciones e impulsividad con la vespertinidad podría facilitar la aparición de trastornos de la conducta alimentaria y de consumo de drogas (Adan et al., 2010; Muro et al., 2011; Natale et al., 2008; Tonetti et al., 2010).

Este trabajo no está exento de limitaciones. Por un lado la propia búsqueda bibliográfica, pues acotamos el análisis a aquellos trabajos publicados entre 1990 y 2012 en lengua castellana o inglesa. Por otro lado, se aprecia una cierta descompensación entre los artículos pertenecientes a diferentes

\section{Referencias}

Abe, M., Herzog, E. D. y Block, G. D. (2000). Lithium lengthens the circadian period of individual suprachiasmatic nucleus neurons. Neuroreport, 11, 3261-3264.

Abe, T., Inoue, Y., Komada, Y., Nakamura, M., Asaoka, S., Kanno, M., ... Takahashi, K. (2011). Relation between morningness-eveningness score and depressive symptoms among patients with delayed sleep phase syndrome. Sleep Medicine, 12, 680-684.

Achari, K. V. y Pati, A. K. (2007). Morningness - eveningness preference in Indian school students as function of gender, age and habitat. Biological Rhythm Research, 38, 1-8.

Adan, A. (1994). Chronotype and personality factors in the daily consumption of alcohol and psychostimulants. Addiction, 89, 455-462.

Adan, A. (2010). Ritmicidad circadiana y adicción. Adicciones, 22, 5-10.

Adan, A. (2013). A chronobiological approach to addiction. Journal of Substance Use, 18, 171-183.

Adan, A. y Almirall, H. (1991). Horne \& Östberg morningness-eveningness questionnaire: A reduced scale. Personality and Individual Differences, 12, 241-253. trastornos. Así, se observa que los artículos publicados en los últimos 12 años sobre depresión cuadriplican aquellos publicados sobre esquizofrenia y duplican los publicados sobre otros trastornos (a excepción de aquellos referentes al trastorno bipolar), lo que dificulta la comparación y generalización de los resultados. Futuros trabajos deberán indagar no tanto en la existencia o no de dichas relaciones sino en el porqué de las mismas, desarrollando modelos explicativos que exploren y evalúen exhaustivamente la aplicabilidad y eficacia de las terapias cronobiológicas en diversos problemas de salud mental.

\section{Conclusiones}

La tipología circadiana ejerce un papel importante en la salud mental. La tipología vespertina es considerada un factor de riesgo para el desarrollo de diversos problemas de salud mental, mientras que la tipología matutina se considera un factor protector. Las asociaciones se observan en múltiples aspectos, tanto en el inicio, curso y remisión de los trastornos como en el riesgo de recaídas. Entre los factores explicativos de dicha asociación destaca la posible implicación de los genes reloj, el jet lag social y las características de personalidad. La terapia cronobiológica puede resultar de utilidad en el tratamiento y prevención de diversos trastornos mentales asociados a la alteración de la ritmicidad circadiana. Por otro lado, es necesario el desarrollo de nuevas investigaciones para profundizar en la etiología y tipo de relación entre tipología circadiana y trastornos mentales, así como estudiar exhaustivamente el papel y la eficacia de la terapia cronobiológica en el tratamiento de diversos trastornos mentales.

Agradecimientos.- Este trabajo se ha realizado gracias a los proyectos de investigación del Ministerio de Ciencia e Innovación (PSI2009-12300) y del Ministerio de Economía y Competitividad (PSI2009-12300) y una beca de Formación de Profesorado Universitario otorgada al primer firmante (AP2010-3244) del Ministerio de Educación, Cultura y Deporte.

Adan, A., Archer, S. N., Hidalgo, M. P., Di Milia, L., Natale, V. y Randler, C. (2012). Circadian typology: A comprehensive review. Chronobiology International, 29, 1153-1175.

Adan, A., Fabbri, M., Natale, V. y Prat, G. (2006). Sleep Beliefs Scale (SBS) and circadian typology. Journal of Sleep Research, 15, 125-132.

Adan, A., Lachica, J., Caci, H. y Natale, V. (2010). Circadian typology and temperament and character personality dimensions. Chronobiology International, 27, 181-193.

Adan, A. y Natale, V. (2002). Gender differences in morningnesseveningness preference. Chronobiology International, 19, 709-720.

Adan, A., Prat, G. y Sánchez-Turet, M. (2004). Effects of nicotine dependence on diurnal variations of subjective activation and mood. Addiction, 99, 1599-1607.

Adan, A. y Sánchez-Turet, M. (2000). Effects of smoking on diurnal variations of subjective activation and mood. Human Psychopharmacology: Clinical and Experimental, 15, 287-293.

Adan, A. y Sánchez-Turet, M. (2001). Gender differences in diurnal variations of subjective activation and mood. Chronobiology International, 18, 491-502. 
Ahn, Y. M., Chang, J., Joo, Y. H., Kim, S. C., Lee, K. Y. y Kim, Y. S. (2008). Chronotype distribution in bipolar I disorder and schizophrenia in a Korean sample. Bipolar Disorders, 10, 271-275.

Anderson, G. (2010). The role of melatonin in post-partum psychosis and depression associated with bipolar disorder. Journal of Perinatal Medicine, 38, 585-587.

Antunes, L. C., da Jornada, M. N., Ramalho, L. y Hidalgo, M. P. (2010). Correlation of shift work and waist circumference, body mass index, chronotype and depressive symptoms. Arquivos Brasileiros de Endocrinologia \& Metabologia, 54, 652-656.

Arushanyan, E. B., Mastyagina, O. A., Mastyagin, S. S. y Popova, A. P. (2005). Fluctuations of the antianxiety effect of valerian and grandaxin during daytime wakefulness in humans with different chronotypes. $\mathrm{Hu}$ man Physiology, 31, 237-238.

Baird, A. L., Coogan, A. N., Siddiqui, A., Donev, R. M. y Thome, J. (2012). Adult attention-deficit hyperactivity disorder is associated with alterations in circadian rhythms at the behavioural, endocrine and molecular levels. Molecular Psychiatry, 17, 988-995.

Barclay, N. L., Eley, T. C., Buysse, D. J., Archer, S. N. y Gregory, A. M. (2010). Diurnal preference and sleep quality: same genes? A study of young adult twins. Chronobiology International, 27, 278-296.

Benedetti, F., Serretti, A., Colombo, C., Barbini, B., Lorenzi, C., Campori, E. y Smeraldi, E. (2003). Influence of CLOCK gene polymorphism on circadian mood fluctuation and illness recurrence in bipolar depression. American Journal of Medical Genetics Part B: Neuropsychiatric Genetics, 123B, 23-26.

Bennett, C. L., Petros, T. V., Johnson, M. y Ferraro, F. R. (2008). Individual differences in the influence of time of day on executive functions. American Journal of Psychology, 121, 349-361.

Caci, H., Bouchez, J. y Baylé, F. J. (2009). Inattentive symptoms of ADHD are related to evening orientation. Journal of Attention Disorders, 13, 36-41.

Caci, H., Deschaux, O., Adan, A. y Natale, V. (2009). Comparing three morningness scales: Age and gender effects, structure and cut-off criteria. Sleep Medicine, 10, 240-245.

Carpen, J. D., von Schantz, M., Smits, M., Skene, D. J. y Archer, S. N. (2006). A silent polymorphism in the PER1 gene associates with extreme diurnal preference in humans. Journal of Human Genetics, 51, 11221125.

Cermakian, N. y Boivin, D. B. (2003). A molecular perspective of human circadian rhythm disorders. Brain Research Reviews, 42, 204-220.

Chong, T. W. H. y Castle, D. J. (2004). Layer upon layer: Thermoregulation in schizophrenia. Schizophrenia Research, 69, 149-157.

Chung, J. K., Lee, K. Y., Kim, S. H., Kim, E. J., Jeong, S. H., Jung, H. Y., ... Joo, E. J. (2012). Circadian rhythm characteristics in mood disorders: Comparison among bipolar I disorder, bipolar II disorder and recurrent major depressive disorder. Clinical Psychopharmacology and Neuroscience, 10, 110-116.

Conroy, D. A., Hairston, I. S., Arnedt, J. T., Hoffman, R. F., Armitage, R. y Brower, K. J. (2012). Dim light melatonin onset in alcohol-dependent men and women compared with healthy controls. Chronobiology International, 29, 35-42.

Crocq, M. A. (2008). Depression and circadian rhythms. WPA Bulletin on Depression, 12, P2.

Dardente, H. y Cermakian, N. (2007). Molecular circadian rhythms in central and peripheral clocks in mammals. Chronobiology International, 24, 195213.

Díaz-Morales, J. F. y Sánchez-López, M. P. (2008). Morningnesseveningness and anxiety among adults: A matter of sex/gender? Personality and Individual Differences, 44, 1391-1401.

Fernández-Mendoza, J., Vela-Bueno, A., Vgontzas, A. N., OlavarrietaBernardino, S., Ramos-Platón, M. J., Bixler, E. O. y De la Cruz-Troca, J. J. (2009). Nighttime sleep and daytime functioning correlates of the insomnia complaint in young adults. Journal of Adolescence, 32, 1059-1074.

Fernández-Ríos, L. y Buela-Casal, G. (2009). Standards for the preparation and writing of psychology review articles. International Journal of Clinical and Health Psychology, 9, 329-344.

Ford, D. E. y Cooper-Patrick, L. (2001). Sleep disturbances and mood disorders: An epidemiologic perspective. Depression and Anxiety, 14, 3-6.

Gammack, J. K. (2008). Light therapy for insomnia in older adults. Clinics in Geriatric Medicine, 24, 139-149.
Gaspar-Barba, E., Calati, R., Cruz-Fuentes, C. S., Ontiveros-Uribe, M. P., Natale, V., De Ronchi, D. y Serretti, A. (2009). Depressive symptomatology is influenced by chronotypes. Journal of Affective Disorders, 119, 100-106.

Germain, A. y Kupfer, D. J. (2008). Circadian rhythm disturbances in depression. Human Psychopharmacology, 23, 571-585.

Giannotti, F., Cortesi, F., Sebastiani, T. y Ottaviano, S. (2002). Circadian preference, sleep and daytime behaviour in adolescence. Journal of Sleep Research, 11, 191-199.

Giglio, L. M., Magalhães, P. V., Andersen, M. L., Walza, J. C., Jakobson, L. y Kapczinski, F. (2010). Circadian preference in bipolar disorder. Sleep and Breathing, 14, 153-155.

Guo, H., Brewer, J. M., Lehman, M. N. y Bittman, E. L. (2006). Suprachiasmatic regulation of circadian rhythms of gene expression in hamster peripheral organs: Effects of transplanting the pacemaker. The Journal of Neuroscience, 26, 6404-6412.

Hasler, B. P., Smith, L. J., Cousins, J. C. y Bootzin, R. R. (2012). Circadian rhythms, sleep, and substance abuse. Sleep Medicine Reviews, 16, 67-81.

Hidalgo, M. P., Caumo, W., Posser, M., Coccaro, S. B., Camozzato, A. L. y Chaves, M. L. (2009). Relationship between depressive mood and chronotype in healthy subjects. Psychiatry and Clinical Neurosciences, 63, 283290.

Hidalgo, M. P. L., de Souza, C. M., Zanette, C. B. y Nunes, P. V. (2003). Association of daytime sleepiness and the morningness/eveningness dimension in young adult subjects in Brazil. Psychological Reports, 93, 427434.

Hsu, C. Y., Gau, S. S. F., Shang, C. Y., Chiu, Y. N. y Lee, M. B. (2012). Associations between chronotypes, psychopathology, and personality among incoming college students. Chronobiology International, 29, 491-501.

Johnson, W. G., Schlundt, D. G., Barclay, D. R., Carr-Nangle, R. E. y Engler, L. B. (1995). A naturalistic functional analysis of binge eating. Behav ior Therapy, 26, 101-118.

Jones, K. H. S., Ellis, J., von Schantz, M., Skene, D. J., Dijk, D. J. y Archer, S. N. (2007). Age-related change in the association between a polymorphism in the PER3 gene and preferred timing of sleep and waking activities. Journal of Sleep Research, 16, 12-16.

Kantermann, T., Theadom, A., Roenneberg, T. y Cropley, M. (2012). Fibromyalgia syndrome and chronotype: Late chronotypes are more affected. Journal of Biological Rhythms, 27, 176-179.

Kasof, J. (2001). Eveningness and bulimic behavior. Personality and Individual Differences, 31, 361-369.

Kennedy, S. H., Kutcher, S. P., Ralevski, E. y Brown, G. M. (1996). Nocturnal melatonin and 24-hour 6-sulphatoxymelatonin levels in various phases of bipolar affective disorder. Psychiatry Research, 63, 219-222.

Kitamura, S., Hida, A., Watanabe, M., Enomoto, M., Aritake-Okada, S., Moriguchi, Y., ... Mishima, K. (2010). Evening preference is related to the incidence of depressive states independent of sleep-wake conditions. Chronobiology International, 27, 1797-1812.

Kledzik, A. M. y Thorne, M. C. (2011). The role of melatonin in psychiatric disorders. Psychopharm Review, 46, 49-55.

KosKenvuo, M., Hublin, C., Partinen, M., Heikkilä, K. y Kaprio, J. (2007) Heritability of diurnal type: a nationwide study of 8753 adult twin pairs. Journal of Sleep Research, 16, 156-162.

Lack, L. y Wright, H. (1993). The effect of evening bright light in delaying the circadian rhythms and lengthening the sleep of early morning awakening insomniacs. Sleep, 16, 436-443.

Lam, R. W., Goldner, E. M. y Grewal, A. (1996). Seasonality of symptoms in anorexia and bulimia nervosa. International Journal of Eating Disorders, 19 , 35-44.

Latzer, Y., Tzischinsky, O., Epstein, R., Klein, E. y Peretz, L. (1999). Naturalistic sleep monitoring in women suffering from bulimia nervosa. In ternational Journal of Eating Disorders, 26, 315-321.

Lavebratt, C., Sjöholm, L. K., Partonen, T., Schalling, M. y Forsell, Y. (2010). Per2 variantion is associated with depression vulnerability. Amer ican Journal of Medical Genetics Part B: Neuropsychiatric Genetics, 153B, 570581.

Leibenluft, E., Albert, P. S., Rosenthal, N. E. y Wehr, T. A. (1996). Relationship between sleep and mood in patients with rapid-cycling bipolar disorder. Psychiatry Research, 63, 161-168. 
Levandovski, R., Dantas, G., Fernandes, L. C., Caumo, W., Torres, I., Roenneberg, T., ... Allebrandt, K. V. (2011). Depression scores associate with chronotype and social jetlag in a rural population. Chronobiology International, 28, 771-778.

Liu, Y., Wang, Y., Jiang, Z., Wan, C., Zhou, W. y Wang, Z. (2007). The extracellular signal-regulated kinase signaling pathway is involved in the modulation of morphine-induced reward by mPer1. Neuroscience, 146, 265-271.

Mansour, H. A., Wood, J., Chowdari, K. V., Dayal, M., Thase, M. E., Kupfer, D. J., ... Nimgaonkar, V. L. (2005). Circadian phase variation in bipolar I disorder. Chronobiology International, 22, 571-584.

Mansour, H. A., Wood, J., Logue, T., Chowdari, K. V., Dayal, M., Kupfer, D. J., ... Nimgaonkar, V. L. (2006). Association study of eight circadian genes with bipolar I disorder, schizoaffective disorder and schizophrenia. Genes, Brain, and Behavior, 5, 150-157.

Martin, J. L., Jeste, D. V. y Ancoli-Israel, S. (2005). Older schizophrenia patients have more disrupted sleep and circadian rhythms than agematched comparison subjects. Journal of Psychiatric Research, 39, 251-259.

Matsuo, M., Shiino, Y., Yamada, N., Ozeki, Y. y Okawa, M. (2007). A novel $\mathrm{SNP}$ in hPer2 associates with diurnal preference in a healthy population. Sleep and Biological Rhythms, 5, 141-145.

McClung, C. A. (2007). Circadian rhythms, the mesolimbic dopaminergic circuit, and drug addiction. The Scientific World Journal, 2, 194-202.

McClung, C. A., Sidiripoulou, K., Vitaterna, M., Takahashi, J. S. y White, F. (2005). Regulation of dopaminergic transmission and cocaine reward by the Clock gene. Proceedings of the National Academy of Sciences of the United States of America, 102, 9377-9381.

McClung, C. R. (2006). Plant circadian rhythms. The Plant Cell, 18, 792-803.

Mecacci, L. y Rocchetti, G. (1998). Morning and evening types: Stressrelated personality aspects. Personality and Individual Differences, 25, 537542.

Meliska, C. J., Martínez, L. F., López, A. M., Sorenson, D. L., Nowakowski, S. y Parry, B. L. (2011). Relationship of morningness-eveningness questionnaire score to melatonin and sleep timing, body mass index and atypical depressive symptoms in peri- and post-menopausal women. Psychiatry Research, 188, 88-95.

Mishima, K., Tozawa, T., Satoh, K., Saitoh, H. y Mishima, Y. (2005). The $3111 \mathrm{~T} / \mathrm{C}$ polymorphism of hClock is associated with evening preference and delayed sleep timing in a Japanese population sample. American Journal of Medical Genetics Part B: Neuropsychiatric Genetics, 133B, 101-104.

Mitterauer, B. (2000). Clock genes, feedback loops and their possible role in the etiology of bipolar disorders: An integrative model. Medical Hypotheses, 55, 155-159.

Mongrain, V. y Dumont, M. (2007). Increased homeostatic response to behavioral sleep fragmentation in morning types compared to evening types. Sleep, 30, 773-780

Morris, M., Lack, L. y Dawson, D. (1990). Sleep-onset insomniacs have delayed temperature rhythms. Sleep, 13, 1-14.

Muro, A., Gomà-i-Freixanet, M., Adan, A. y Cladellas, R. (2011). Circadian typology, age, and the alternative Five-Factor Personality Model in an adult women sample. Chronobiology International, 28, 690-696.

Natale, V., Adan, A. y Scapellato, P. (2005). Are seasonality of mood and eveningness closely associated? Psychiatry Research, 136, 51-60.

Natale, V., Ballardini, D., Schumann, R., Mencarelli, C. y Magelli, V. (2008). Morningness-eveningness preference and eating disorders. Personality and Individual Differences, 45, 549-553.

Natale, V., Martoni, M. y Cicogna, P. (2003). Effects of circadian typology on sleep-wake behavior of air traffic controllers. Psychiatry and Clinical Neurosciences, 57, 539-541.

Nievergelt, C. M., Kripke, D. F., Barret, T. B., Burg, E., Remick, R. A., Sadovnick, A. D., ... Kelsoe, J. R. (2006). Suggestive evidence for association of the circadian genes PERIOD3 and ARNTL with bipolar disorder. American Journal of Medical Genetics Part B: Neuropsychiatric Genetics, 141B, 234-241.

Nurnberger, J. I. Jr., Berrettini, W., Simmons-Alling, S., Lawrence, D. y Brittain, H. (1990). Blunted ACTH and cortisol response to afternoon tryptophan infusion in euthymic bipolar patients. Psychiatry Research, 31, 5767 .
Ong, J. C., Huang, J. S., Kuo, T. F. y Manber, R. (2007). Characteristics of insomniacs with self-reported morning and evening chronotypes. Journal of Clinical Sleep Medicine, 3, 289-294.

Pabst, S. R., Negriff, S., Dorn, L. D., Susman, E. J. y Huang, B. (2009). Depression and anxiety in adolescent females: The impact of sleep preference and body mass index. Journal of Adolescent Health, 44, 554-560.

Prat, G. y Adan, A. (2011). Influence of circadian typology on drug consumption, hazardous alcohol use, and hangover symptoms. Chronobiology International, 28, 248-257.

Perreau-Lenz, S., Zghoul, T., de Fonseca, F. R., Spanagel, R. y Bilbao, A. (2009). Circadian regulation of central ethanol sensitivity by the mPer2 gene. Addiction Biology, 14, 253-259.

Putilov, A. A. (2008). Association of morning and evening lateness with selfscored health: Late to bed and early to rise makes a man healthy in his own eyes. Biological Rhythm Research, 39, 321-333.

Quera-Salva, M. A., Hartley, S., Barbot, F., Álvarez, J. C., Lofaso, F. y Guilleminault, C. (2011). Circadian rhythms, melatonin and depression. Current Pharmaceutical Design, 17, 1459-1470.

Rand, C. S. W., Macgregor, A. M. C. y Stunkard, A. J. (1997). The night eating syndrome in the general population and among postoperative obesity surgery patients. International Journal of Eating Disorders, 22, 65-69.

Randler, C. (2008a). Morningness-eveningness comparison in adolescents from different countries around the world. Chronobiology International, 25, 1017-1028.

Randler, C. (2008b). Differences between smokers and nonsmokers in morningness-eveningness. Social Behavior and Personality: an international journal, 36, 673-680.

Randler, C. (2011). Association between morningness-eveningness and mental and physical health in adolescents. Psychology, Health \& Medicine, 16, 29-38.

Roenneberg, T., Kuehnle, T., Pramstaller, P. P., Ricken, J., Havel, M., Guth, A. y Merrow, M. (2004). A marker for the end of adolescence. Current Biology, 14, R1038-R1039.

Ryan, M. C., Sharifi, N., Condren, R. y Thakore, J. H. (2004). Evidence of basal pituitary-adrenal overactivity in first episode, drug naïve patients with schizophrenia. Psychoneuroendocrinology, 29, 1065-1070.

Rybak, Y. E., McNeely, H. E., Mackenzie, B. E., Jain, U. R. y Levitan, R. D. (2006). An open trial of light therapy in adult attentiondeficit/hyperactivity disorder. The Journal of Clinical Psychiatry, 67, 15271535

Rybak, Y. E., McNeely, H. E., Mackenzie, B. E., Jain, U. R. y Levitan, R. D. (2007). Seasonality and circadian preference in adult attentiondeficit/hyperactivity disorder: Clinical and neuropsychological correlates. Comprehensive Psychiatry, 48, 562-571.

Schmidt, C., Collette, F., Cajochen, C. y Peigneux, P. (2007). A time to think: Circadian rhythms in human cognition. Cognitive Neuropsychology, 24, 755789 .

Schmidt, S. y Randler, C. (2010). Morningness-eveningness and eating disorders in a sample of adolescent girls. Journal of Individual Differences, 31 , 38-45.

Schubert, E. y Randler, C. (2008). Association between chronotype and the constructs of the Three-Factor-Eating-Questionnaire. Appetite, 51, 501505.

Selvi, Y., Aydin, A., Boysan, M., Atli, A., Agargun, M. Y. y Besiroglu, L. (2010). Associations between chronotype, sleep quality, suicidality, and depressive symptoms in patients with major depression and healthy controls. Chronobiology International, 27, 1813-1828.

Silva, M. M. A., Albuquerque, A. M. y Araujo, J. F. (2005). Light-dark cycle synchronization of circadian rhythm in blind primates. Journal of Circadian Rhythms, 3, 10

Soreca, I., Fagiolini, A., Frank, E., Goodpaster, B. H. y Kupfer, D. J. (2009). Chronotype and body composition in bipolar disorder. Chronobiology International, 26, 780-788.

Soria, V., Martínez-Amorós, E., Escaramís, G., Valero, J., Pérez-Egea, R., García, C., ... Urretavizcava, M. (2010). Differential association of circadian genes with mood disorders: CRY1 and NPAS2 are associated with unipolar major depression and CLOCK and VIP with bipolar disorder. Neuropsychopharmacology, 35, 1279-1289.

Takeuchi, H., Oishi, T. y Harada, T. (2005). Association between moringness-eveningness preference and mental/physical premenstrual symp- 
toms in Japanese females 12 to 31 years of age. Chronobiology International, 22, 1055-1068.

Tankova, I., Adan, A. y Buela-Casal, G. (1994). Circadian typology and individual differences. A review. Personality and Individual Differences, 16, 671684.

Taylor, D. J., Clay, K. C., Bramoweth, A. D., Sethi, K. y Roane, B. M. (2011). Circadian phase preference in college students: relationships with psychological functioning and academics. Chronobiology International, 28, 541-547.

Tonetti, L., Adan, A., Caci, H., De Pascalis, V., Fabbri, M. y Natale, V. (2010). Morningness-eveningness preference and sensation seeking. European Psychiatry, 25, 111-115.

Tonetti, L., Fabbri, M. y Natale, V. (2009). Relationship between circadian typology and big five personality domains. Chronobiology International, 26, 337-347.

Tzischinsky, O. y Shochat, T. (2011). Eveningness, sleep patterns, daytime functioning, and quality of life in Israeli adolescents. Chronobiology International, 28, 338-343.

Urbán, R., Magyaródi, T. y Rigó, A. (2011). Morningness-eveningness, chronotypes and health-impairing behaviors in adolescents. Chronobiology International, 28, 238-247.

Vernet, C. y Arnulf, I. (2009). Idiopathic hypersomnia with and without long sleep time: A controlled series of 75 patients. Sleep, 32, 753-759.

Voinescu, B. I., Szentagotai, A. y David, D. (2012). Sleep disturbance, circadian preference and symptoms of adult attention deficit hyperactivity disorder (ADHD). Journal of Neural Transmission, 119, 1195-1204.
Vosko, A. M., Colwell, C. S. y Avidan, A. Y. (2010). Jet lag syndrome: Circadian organization, pathophysiology, and management strategies. Nature and Science of Sleep, 2, 187-198.

Wehr, T. A. (2001). Photoperiodism in humans and other primates: Evidence and implications. Journal of Biological Rhythms, 16, 348-364.

Wirz-Justice, A. (2003). Chronobiology and mood disorders. Dialogues in Clinical Neuroscience, 5, 315-325.

Wirz-Justice, A. (2008). Diurnal variation of depressive symptoms. Dialogues in Clinical Neuroscience, 10, 337-343.

Wirz-Justice, A., Benedetti, F., Berger, M., Lam, R. W., Martiny, K., Terman, M. y Wu, J. C. (2005). Chronotherapeutics (light and wake therapy) in affective disorders. Psychological Medicine, 35, 939-944.

Wirz-Justice, A., Terman, M., Oren, D. A., Goodwin, F. K., Kripke, D. F. Whybrow, P. C., ... van den Hoofdakker, R. H. (2004). Brightening depression. Science, 303, 467-469.

Wittmann, M., Dinich, J., Merrow, M. y Roenneberg, T. (2006). Social jetlag: Misalignment of biological and social time. Chronobiology International, 23, 497-509.

Wood, J., Birmaher, B., Axelson, D., Ehmann, M., Kalas, C., Monk, K., ... Nimgainkar, V. L. (2009). Replicable differences in preferred circadian phase between bipolar disorder patients and control individuals. Psychiatry Research, 166, 201-209.

Zhang, J., Liao, G., Liu, C., Sun, L., Liu, Y., Wang, Y., ... Wang, Z. (2011). The association of CLOCk gene T3111C polymorphism and hPER3 gene 54-nucleotide repeat polymorphism with Chinese Han people schizophrenics. Molecular Biology Reports, 38, 349-354.

(Artículo recibido: 25-9-2012; revisión recibida: 15-2-2013; aceptado: 13-9-2013) 